\title{
Experimental analysis of aluminium/carbon epoxy hybrid laminates under flexural load
}

\author{
Costanzo Bellini, Vittorio Di Cocco, Francesco Iacoviello, Luca Sorrentino \\ Department of Civil and Mechanical Engineering, University of Cassino and Southern Lazio, 03043 Cassino, Italy \\ costanzo.bellini@unicas.it, bttp://orcid.org/0000-0003-4804-6588 \\ vittorio.dicocco@unicas.it, bttp:/ / orcid.org/0000-0002-1668-3729 \\ francesco.iacoviello@unicas.it, http:/ /orcid.org/0000-0002-9382-6092 \\ luca.sorrentino@unicas.it, bttp://orcid.org/0000-0002-5278-7357
}

ABSTRACT. Industry needs new materials that present very high structural characteristic, such as high strength, low weight and high damage tolerance. To obtain these characteristics a new class of materials has been introduced: Fibre Metal Laminate (FML); they consist in metal sheets alternated to composite material layers: in such manner, the good characteristics of each constituent material confer the utmost properties to the FMLs. However, the mechanical properties depend, among other factors, on the thickness and the numerousness of the layers constituting the FML, as well as the interface between metal and composite. Therefore, in this paper, the influence of the abovementioned factors on the material answer to flexural load was investigated. In particular, different kinds of laminates were produced varying the layers adhesion and the layers thickness, but maintaining unaltered the metal/composite volume ratio and the total laminate thickness. Then their structural behaviour was investigated through three-point bending test, and it was found that the flexural behaviour was affected by both the investigated factors; in fact, the maximum flexural load diminished incrementing the number of layers and inserting an adhesive layer at the metal/composite interface.

KEYWORDS. Fibre metal laminate; Flexural load; Structural behaviour.

\section{OPEN ACCESS}

Citation: Bellini, C., Di Cocco, V, Iacoviello, F., Sorrentino, L., Experimental analysis of aluminium carbon/epoxy hybrid laminates under flexural load, Frattura ed Integrità Strutturale, 49 (2019) 739-747.

Received: 24.05.2019

Accepted: 22.06 .2019 Published: 01.07.2019

Copyright: (C) 2019 This is an open access article under the terms of the CC-BY 4.0, which permits unrestricted use, distribution, and reproduction in any medium, provided the original author and source are credited.

\section{INTRODUCTION}

S everal industrial fields, like automotive, aeronautics and sports goods, need new materials presenting very high structural characteristics, such as high strength, low weight and high damage tolerance. These characteristics can be obtained by introducing a new class of materials: Fibre Metal Laminate (FML); they consist of metal sheets alternated to composite material layers: in such manner, the good characteristics of each constituent material confer the utmost 
properties to the FMLs, such as high strength, high damage tolerance and low density [1]. These extraordinary structural properties are due to the particular characteristics of the materials the FMLs are made of; in fact, the FMLs made of aluminium and glass fibre composite, that are widespread in the aeronautical field, are less robust than those based on CFRP (carbon fibre reinforced polymer) [2]; in fact, CARALL (carbon fibre-reinforced aluminium laminates) are about 10\% tougher than GLARE (glass fibre reinforced aluminium laminates) [3]. In general, carbon-based FMLs present superior characteristics, as regards the ability to withstand crashes, energy absorption capacity, tensile modulus, yield strength and fatigue strength, in comparison with glass fibre or aramid-based FMLs [4]. The FMLs can be considered for ballistic applications too, together with aramid fibre composites [5].

Usually, structural parts are subjected to flexural loads, that represents the most diffused, and consequently most studied failure mode. The elements an FML is made of have dissimilar properties, causing a complex damage behaviour; in fact, the composite layers are brittle, while metal layers are ductile. The most diffused failure mechanisms of FLMs are matrix cracking, metal layers plastic deformation, fibres fracture, composite layers delamination and debonding between metal and composite [6]. Hu et al. [7] analysed the flexural properties of FMLs made of carbon fibres reinforced PMR polyimide and titanium, finding a good structural strength at both room and high temperature. They also found that the micro roughness of the titanium surface layer improved the adhesion between composite material and titanium itself. Lawcock et al. [8] found that the bending characteristics of CARALL depend on the adhesion between the composite laminate and the aluminium layers, while the tensile properties are not affected; in fact, a weak bonding can give rise to a decrement of about $10 \%$ for the interlaminar shear strength. They determined that the bonding strength did not influence the residual strength of notched specimen, even if a small decrease for a specimen with a stronger bonding was found. A similar result was stated by Botelho et al. [9] that treated the aluminium surface with two different processes: sulphuric chromic acid etching and chromic acid anodization. They found that the latter method brought to better surface wetting, but the interlaminar shear strength of both GLARE and CARALL was not influenced. The effect of the metal sheet location along the laminate thickness was studied by Dhaliwal and Newaz [10], that produced and tested some CARALL specimens presenting carbon fibre laminate as outside layers. They compared the flexural properties of those laminates with that of common CARALL, that had aluminium layers outside, determining a superior strength for their material. They also made a comparison between CARALL and bulk aluminium specimens, determined a higher bending strength of the former ones. The effect of the aluminium sheet strength and the fibres directions on the in-plane flexural behaviour of CARALLs was analysed by Xu et al. [2]. They discovered an increment of the flexural strength as both the amount of the longitudinal fibres and the metal strength were increased. As regards the progressive failure process, at first the aluminium sheets yield appeared, together with tension damage of fibre and resin in the section bottom and resin compression crushing in the section top; after, the delamination started in the laminate mid-span, caused by the unstable deformation. A work has been carried out aiming at analysing the behaviour of laminates with the same composite/metal volume fraction ratio and different layers thicknesses by Wu et al. [11]. These authors studied the flexural behaviour of carbon fibre/magnesium FMLs, discovering that the flexural modulus linearly decreased with the layer thicknesses, while no differences were observed for the flexural strength. However, the layer thickness decrease made the failure area shift from compression to tension region. Moreover, the bonding behaviour is fundamental for composites and FMLs [12,13].

The aim of the present work regards the analysis of the flexural behaviour of CARALL specimens, studying the influence of both layer thickness and the adhesion solution between CFRP laminate and aluminium sheet. In particular, the attention was paid not only to the maximum flexural strength reached by the specimens, but also to the stress-strain response after the first elastic phase and the first stress peak, that represents the maximum stress. In this manner, it is possible to determine also which parameter combination presents the highest toughness and the highest safety after the first peak stress. Moreover, unidirectional reinforcements are usually employed in the design of FMLs, while in this study a carbon fabric was considered as composite material reinforcement. The effect of the stacking characteristic on the laminate mechanical behaviour was studied by several researchers, even if they keep the composite laminate thickness [14,15] or metal sheet thickness $[16,17]$ constant and focused the attention on the dynamic characterization. The layer thickness is a significant factor concerning the structural behaviour of FMLs that should be taken into consideration for the product design, even if the study of this topic has been infrequently explored [11].

\section{MATERIALS AND METHODS}

I

$\mathrm{n}$ this work, the effects of layer thickness and of the layer adhesion were investigated both separately and combined. As reported in Tab. 1, four different specimen types composed the full factorial plan of the experimental activity, that 
presented 2 levels for each factor. The analysis was carried out through three-point bending tests on the CARALL specimens with different stacking and dissimilar bonding strategy.

\begin{tabular}{ccc}
\hline Specimen type & Number of metal sheet & Adhesive \\
Type A & 1 & yes \\
Type B & 1 & no \\
Type C & 2 & yes \\
Type D & 2 & no \\
\hline
\end{tabular}

Table 1: Full factorial plan for factor influence analysis.

As concerns the stacking sequence, two laminates with CFRP laminate as external layer were considered; in particular, one consisted of two layers of CFRP and one of aluminium, while the other one was formed by two layers of aluminium and three layers of carbon fibre. In order to maintain the laminate thickness and the CFRP/aluminium ratio constant, the aluminium sheet thickness of the former typology was equal to $0.6 \mathrm{~mm}$ and one composite laminate was composed by six prepreg plies, for a total of 12 plies, while the latter type presented two $0.3 \mathrm{~mm}$ thick aluminium foil and three CFRP layers consisting of four prepreg plies each. In such a manner, the obtained laminate thickness was $5 \mathrm{~mm}$. In order to evaluate the influence of the adhesive interface between the composite material and the aluminium sheet on the mechanical performance of the hybrid laminates, both FMLs with and without adhesive were produced and tested. In particular, for the former ones a structural adhesive, typically used in the aeronautical field, was adopted, while the bonding interface of the latter ones relied on the self-adhesive capacity of the resin being a part of the prepreg material. The different types of FML studied in the present work are reported in Fig. 1. Four specimens were tested for each set of parameters, so 16 flexure tests were carried out in total.

a)

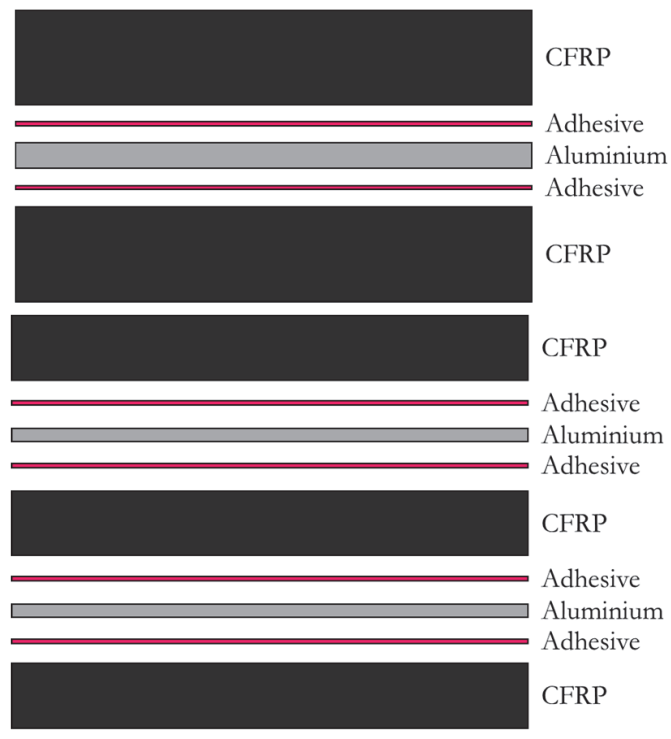

b)

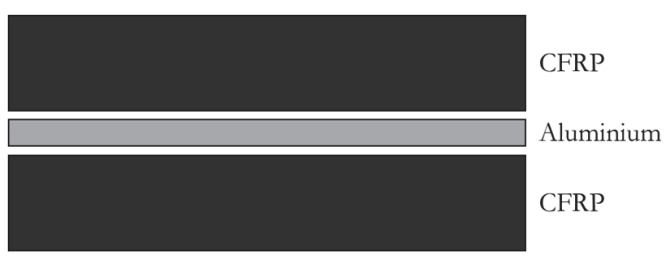

d)

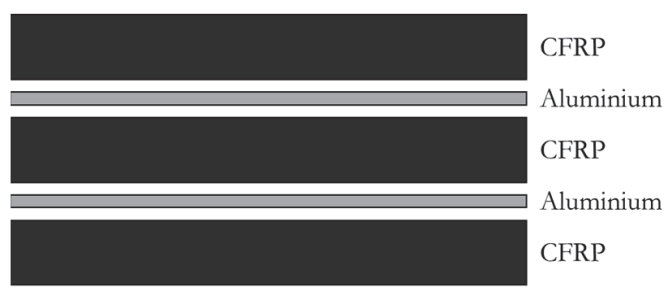

Figure 1: Different kinds of FML considered in this work: a) one metal sheet with adhesive, b) one metal sheet without adhesive, c) two metal sheets with adhesive, d) two metal sheets without adhesive.

The metal sheets considered for this work were made of aluminium Al 1100, while the composite material was the SE70/RC303T/1270/38\%, a prepreg system made of SE70 epoxy resin and a carbon twill style fabric. $2 \times 2$ twill is a weaving style that provides a diagonal pattern with one or more warp fibres woven in a regular manner above and below two or more weft fibres; the warp and weft are the sets of threads that together contribute to the creation of the fabric. The resin weight content was $38 \%$ and the fabric areal density was $303 \mathrm{~g} / \mathrm{m}^{2}$. As concerns the bonding agent used in some specimens, 
it was the AF163-2k film adhesive. It had a thickness of about $0.24 \mathrm{~mm}$ and a carrier, made of glass fibres, was present inside it for resistance increment purpose.

As regards the manufacturing process of the CARALL specimens, four laminates, one for each FML type considered in this work, were produced by the vacuum bag process. The mould consisted of a $10 \mathrm{~mm}$ thick steel plate, whose dimensions were $500 \times 400 \mathrm{~mm}^{2}$, on which the four laminates were produced simultaneously, since the mould area was enough ample. In fact, it was decided to produce laminates with dimensions equal to $200 \times 110 \mathrm{~mm}^{2}$, from which extract four specimens with dimensions of $160 \times 20 \mathrm{~mm}^{2}$. The vacuum bag is a manufacturing process typically adopted in the aeronautical industries for composite material parts production. For the purpose of the present work, the mould surface was treated with Marbocote, a release agent necessary to warrant a safe part removal at the end of the manufacturing process, without part damage or breakage. Then, all the materials required for CARALLs manufacturing, that were the prepreg plies, the aluminium sheets and the adhesive plies, were cut into the right size and stacked as described in Fig. 2. Then, the four stacks were covered with a release film and a breather fabric: the latter was needed for evacuating air and gases out of the bag, while the former was used to separate the breather from the laminates. A caul plate was placed on the top prepreg layer to obtain a smooth surface finish on both laminate sides. Finally, the mould was closed with the vacuum bag, closed with a butyl sealant tape, and the vacuum was applied and maintained until the thermal cycle end. After the mould preparation, the parts were polymerized in an autoclave following the thermal cycle suggested by the prepreg manufacturer, that was suitable for the adhesive cure too. In fact, the cure process is a very important step in polymeric material manufacturing $[18,19]$. This cycle scheduled a heating ramp with a rate of $2{ }^{\circ} \mathrm{C} / \mathrm{min}$ and a temperature dwell of $100 \mathrm{~min}$ at $100{ }^{\circ} \mathrm{C}$. At the end of the curing process, the laminates were taken from the mould and trimmed by a diamond disk saw, obtaining the desired specimens. The produced specimens for type A FML are visible in Fig. 3.

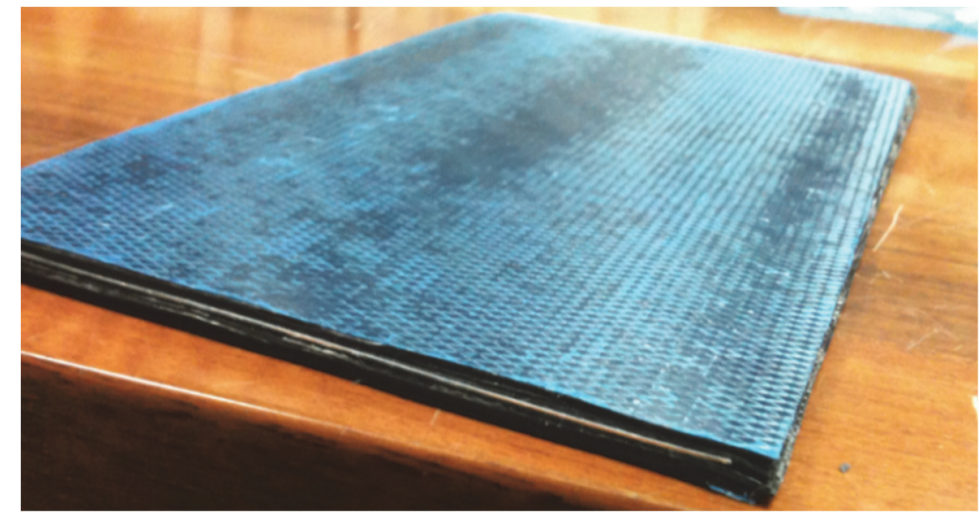

Figure 2: Prepreg plies and aluminium sheets after the stacking phase.

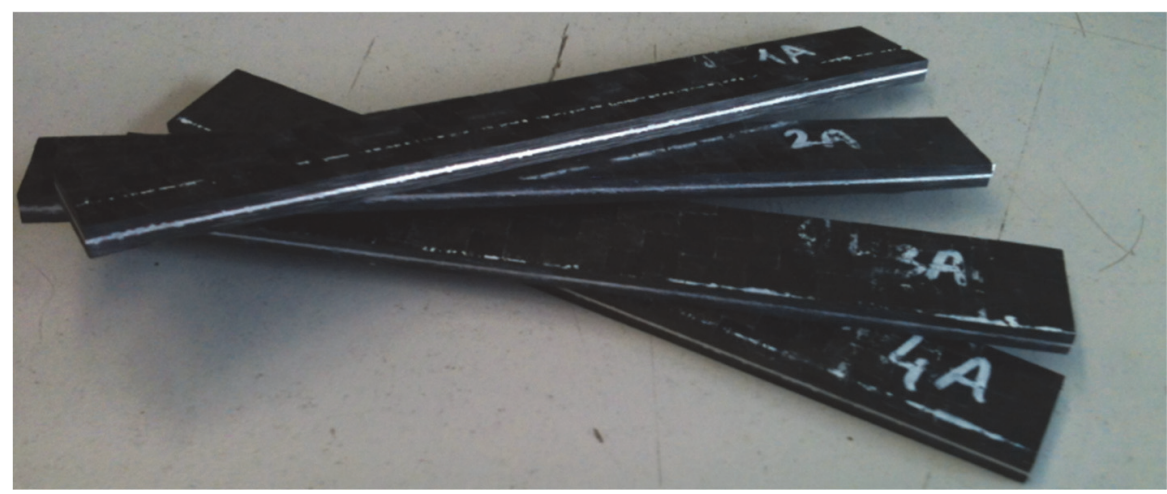

Figure 3: Specimens cut from the FML plates.

The bending tests carried out on the specimens to evaluate the flexural characteristic referred to the ASTM D790. This test method considered a three-point loading system applied to a simply supported beam. In particular, the test involved two cylindrical shape supports on which the rectangular cross-section specimen was laid, loaded by a cylindrical punch, halfway 
between the two supports, as visible in Fig. 4. The span between the support was set to $136 \mathrm{~mm}$, while the loading rate to $6 \mathrm{~mm} / \mathrm{min}$. The specimens were loaded until the loading nose reached a stroke of $27 \mathrm{~mm}$ and then unloaded in order to evaluate the mechanical behaviour of the studied material, even after the maximum load, and so the maximum flexural strength, had been reached.

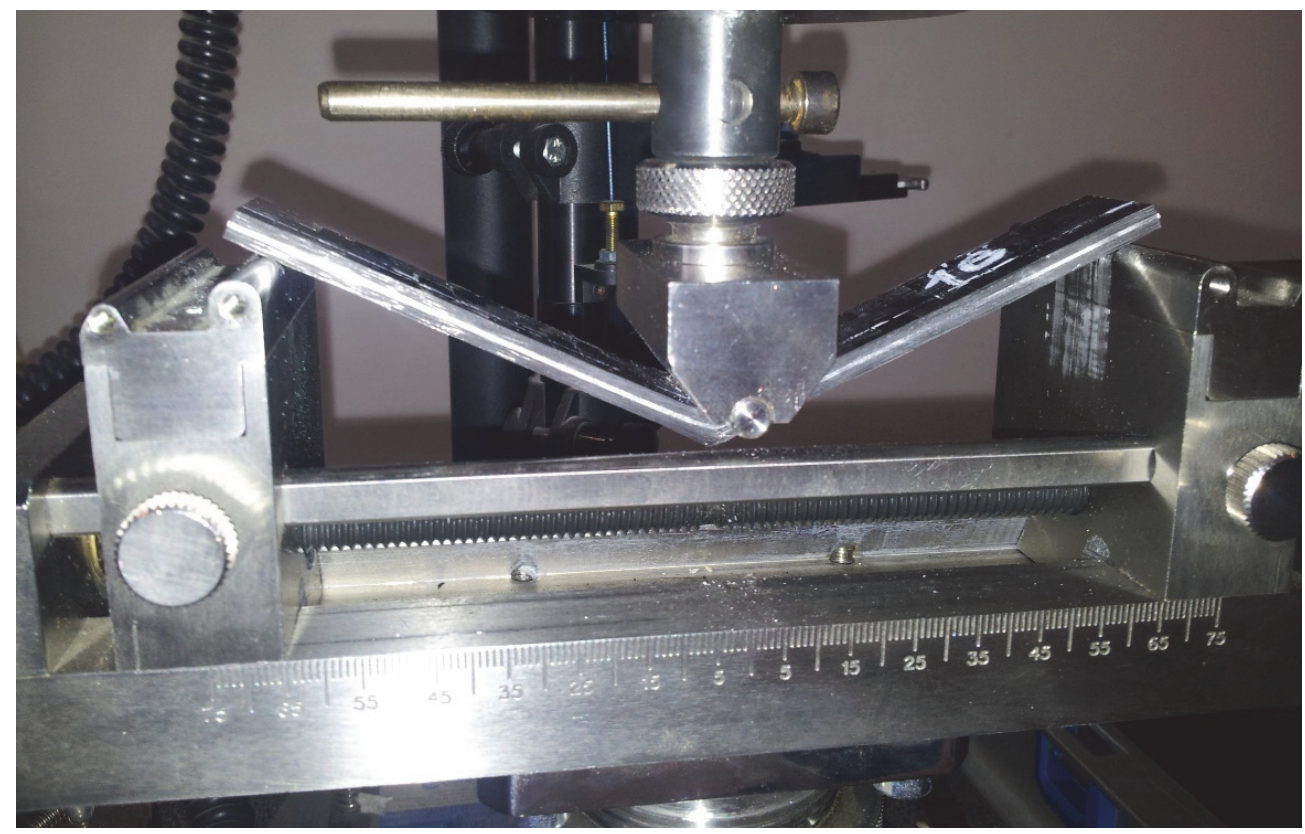

Figure 4: Three-point bending test for type B specimen.

\section{RESULTS AND DISCUSSION}

he influence of two factors, such as the number of layers and the presence of the adhesive, on the flexural properties of the CARALL was studied in this work. In particular, the attention was focused not only on the single factor but also on their combination, leading to a more accurate and deeper interpretation of the material behaviour. The threepoint bending test results concerned the flexural strength and they were analysed through inferential statistical techniques in order to ascertain the presence or absence of significant differences. For the purposes of the present paper, the assumption of equality of all population means was assumed as the null hypothesis, as commonly done for statistical analysis of data characterized by homoscedasticity, normal population distribution and independency of experimental runs. The observation of the $\mathrm{p}$-value was chosen as criteria for null hypothesis rejection: if its value was below the significance level of 0.05 , the generally adopted significance value, then the null hypothesis could be rejected and, consequently, the population means were effectively dissimilar and the influence of the studied factor could not be neglected.

The flexural strength of the tested laminates, denoted as $\sigma_{\mathrm{f}}$, was determined through the following relation, present in ASTM D790 standard and other papers in the literature [10,20,21]:

$$
\sigma_{f}=\frac{3 P L}{2 b d^{2}}
$$

where $\mathrm{P}$ represents the load the specimen undergoes, $\mathrm{L}$ is the distance between the supports and $\mathrm{h}$ and $\mathrm{b}$ are the specimen thickness and width, respectively. As it can be noted in Tab. 2 and Fig. 5, the flexural strength ranged between $562.75 \mathrm{MPa}$ and $641.86 \mathrm{MPa}$ for the laminate with one aluminium sheet bonded with adhesive, while it oscillated between $644.25 \mathrm{MPa}$ and $734.00 \mathrm{MPa}$ for the same laminate without the adhesive, in which the composite material bonding on aluminium sheet was assured by the sole prepreg resin. As concerns the CARALL with two metal layers, the flexural strength interval went from $468.88 \mathrm{MPa}$ to $553.30 \mathrm{MPa}$ for the laminate with adhesive and from 498.38 to 641.38 for that one without adhesive. The CoV (Coefficient of Variation) was low for all the CARALL types; in fact, it was equal to about 5-7\%, and in only one 
case it overcame $10 \%$, even if only for a very small amount. It is worth to note that the results found in this experimental campaign are in accordance with other works on this class of material $[10,22,23]$.

It can be noted from the experimental results that the highest strength value came from the laminate without the adhesive film and with only a metal sheet, while the lowest value to that one with two aluminium sheets and glued with adhesive. It can be stated that the presence of the adhesive film was detrimental for the material strength, whereas the decrease of metal sheets number was positive. As concerns the former conclusion, it seemed to be in contradiction with past literature; in fact, several researchers $[8,24,25]$ discovered an improvement due to the presence of the adhesive, but it must be underlined that the enhancement was found only for lap shear and interlaminar shear tests, while the in-plane mechanical properties, as the tensile strength, showed a similar behaviour. Only in the work of Li et al. [25] the flexural behaviour was considered, but the same authors acknowledged their results to be highly depending on specimen and test geometry.

\begin{tabular}{ccccc}
\hline Run & Type A & Type B & Type C & Type D \\
1 & 562.75 & 658.22 & 497.84 & 542.37 \\
2 & 641.86 & 644.25 & 468.88 & 498.45 \\
3 & 602.50 & 655.68 & 534.33 & 641.38 \\
4 & 621.18 & 734.00 & 553.30 & 563.26 \\
\hline Mean & 607.07 & 673.04 & 513.59 & 561.36 \\
St. dev. & 33.64 & 41.09 & 37.66 & 59.79 \\
CV\% & $5.54 \%$ & $6.11 \%$ & $7.33 \%$ & $10.65 \%$ \\
\hline
\end{tabular}

Table 2: Flexural strength [MPa] for all the tested specimen.

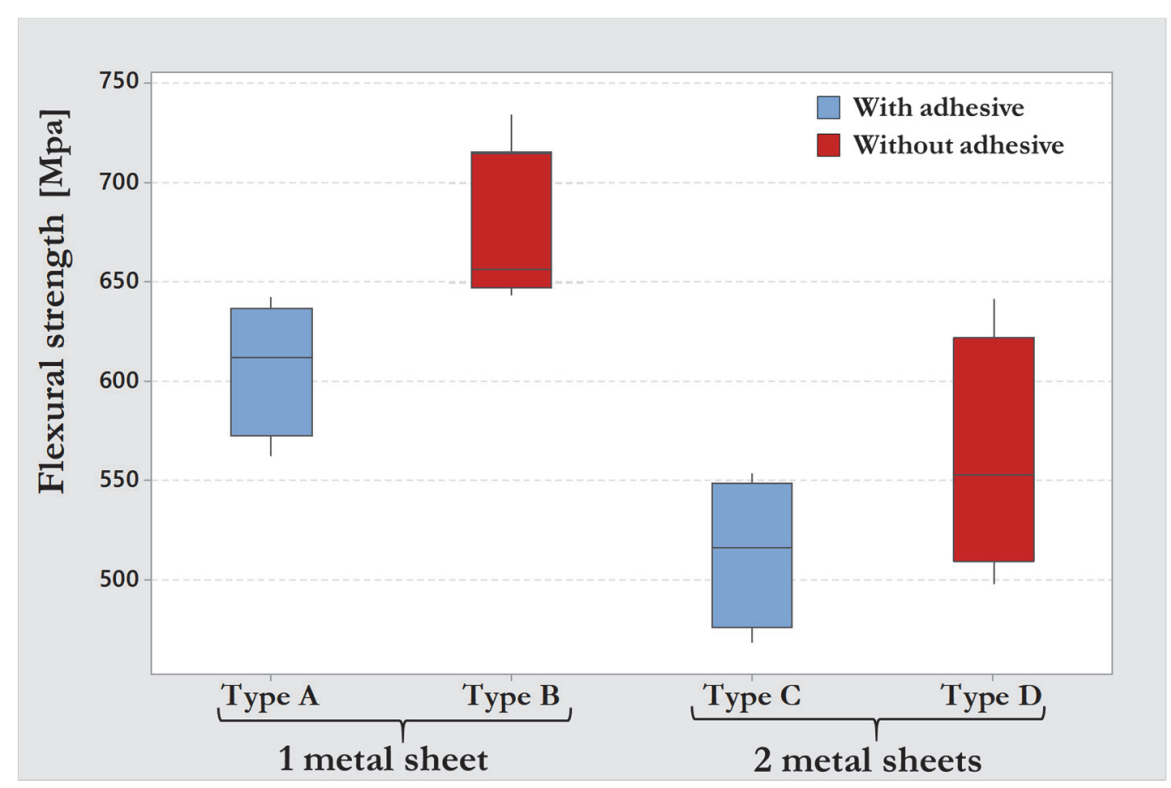

Figure 5: Comparison of flexural strength for the different type of CARALL.

The results of the analysis of variance that was implemented on the experimental results are presented in Tab. 3. It can be noted that the number of aluminium sheets was the most influencing factor, since it had a contribution of $53.41 \%$, while the effect of the other factor, that is the presence of the adhesive, was far less important (16.42\%). The contribution of the 
interaction between factors was less than $0.5 \%$ and it can be neglected. However, for a more significant comparison the pvalue was calculated too for each factor; the analysis confirmed that both the considered factors had an effect on the material flexural strength, since their value was less than 0.05 , the commonly chosen a-level, instead the interaction term p-value was 0.688 and so it can be disregarded.

\begin{tabular}{cccccccc}
\hline Source & DF & Seq SS & Contribution & Adj SS & Adj MS & F-Value & P-Value \\
n. sheets & 1 & 42087.7 & $53.41 \%$ & 42087.7 & 42087.7 & 21.55 & 0.001 \\
adhesive & 1 & 23937.6 & $16.42 \%$ & 12937.6 & 12937.6 & 6.62 & 0.024 \\
$\begin{array}{c}\text { n. sheet } * \\
\text { adhesive }\end{array}$ & 1 & 330.9 & $0.42 \%$ & 330.9 & 330.9 & 0.17 & 0.688 \\
error & 12 & 23439.7 & $29.75 \%$ & 23439.7 & 1953.3 & & \\
total & 15 & 78795.9 & $100.00 \%$ & & & & \\
\hline
\end{tabular}

Table 3: ANOVA analysis of experimental data.

The flexural stress-strain curves of the tested specimens are reported in Fig. 6; in particular, a representative curve is shown for each specimen type since the data scatter was quite limited. The mechanical behaviour of all the four specimens was quite similar; in fact, they presented a first stress increment, almost linear till the maximum stress value was reached, followed by a pseudo-ductile behaviour, with a fluctuating trend characterized by stress increment and decrement. However, there are substantial differences, especially in the second pseudo-ductile phase and, as abovementioned, the maximum stress level obtained. On the contrary, in the first elastic phase the slope of the stress-strain curve, that represents Young's modulus of the material, was quite the same for all the laminates, even if that slope was slightly steeper for the laminate without the adhesive. This conclusion can be justified by the fact that the adhesive is less stiff than the other materials and consequently it made the module of the whole laminate decrease. As concerns the post-first stress peak behaviour, the type A and type D laminates presented the highest stress drop, while for the type $B$ and type $C$ the drop was more reduced. In fact, the type A laminate lost about the $55 \%$ of its load capacity, while the type $\mathrm{D}$ about the $45 \%$; this loss was equal to $20 \%$ for the type $\mathrm{B}$ and $2 \%$ for the type $\mathrm{C}$ specimen. After the stress drop there is a stress recovery for all the laminates, but the value of the second peak is quite different depending on the specimen type; in fact, for the type $\mathrm{C}$ the second peak value is quite similar to the first peak one, for the type B it corresponded to the $90 \%$ of the first peak while for the remaining laminates it was slightly higher than the drop value. These trends show that the type $\mathrm{C}$ laminate is the safest one, although it had the lowest flexural strength, since the stress drop after the first stress peak is low and the value of the second peak stress is like the first one. Finally, it must be noted that the residual load capacity at the end of the test is negligible for the all the specimen except the type D.

\section{CONCLUSIONS}

$\mathrm{F}$ ML materials, that consist of composite layers alternated to metal sheets, are more and more adopted in several industrial fields due to their very high mechanical characteristics features. In this work, the mechanical behaviour of different types of FML was analysed, investigating the effect of the staking sequence and the adhesive presence at the interface between metal and composite material. In this study, aluminium was considered for the metal part of the FML, while the composite material consisted of an epoxy resin reinforced by carbon fabric. The flexural behaviour of the produced laminates was analysed, paying attention not only to the maximum strength but also to the post-peak stress behaviour. The produced laminates had the same thickness and the same metal/composite material ratio, but the material distribution along the thickness was dissimilar in order to obtain different layer thickness without changing the surface density of the panels. From the test results it can be concluded that the highest strength was reached by the laminate with a single metal sheet and without adhesive, while the worst condition was represented by that one with two metal sheets and the presence of the adhesive; in fact, passing from the latter to the former there is a strength increment of about $30 \%$. As concerns the specimens 
behaviour after the maximum stress, various stress trends were noticed: an elevated stress drop characterized the type A and type D specimens, while for the other two laminates types it was reduced or quite absent. In the light of this analysis, it can be concluded that the specimen with two metal sheet and the adhesive was the safer one since it was able to sustain a load near to the maximum one for a long strain interval, even if it presented the lowest maximum stress.

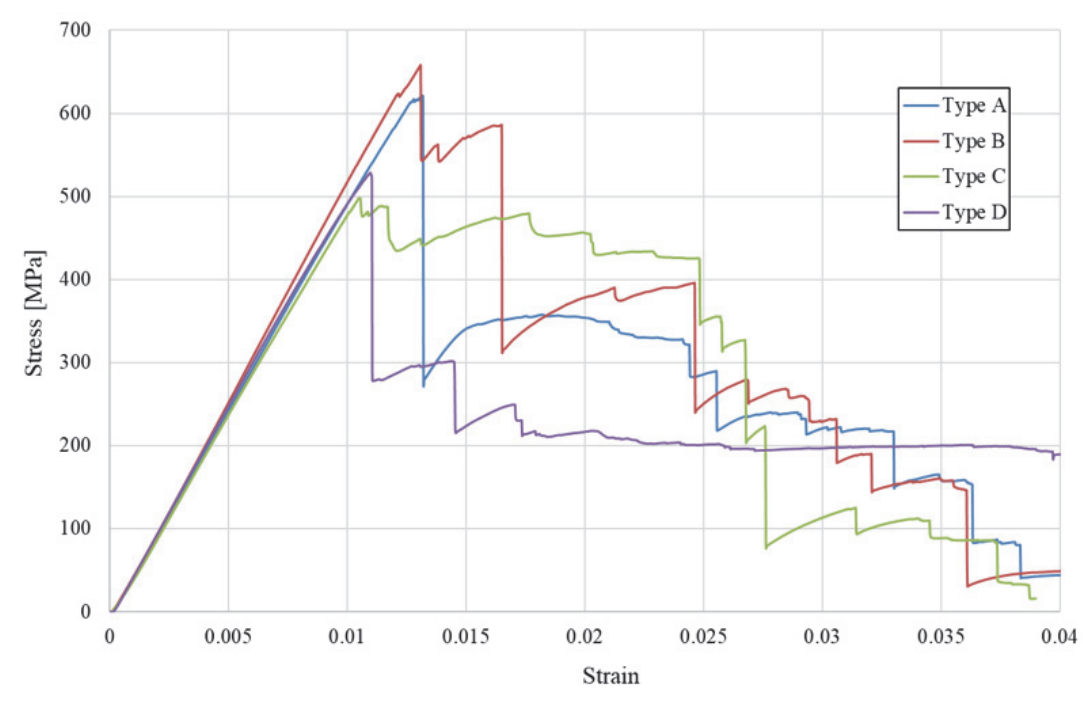

Figure 6: Flexural stress-strain curves of the tested specimens.

\section{REFERENCES}

[1] Vermeeren, C.A.J.R. (2003). An Historic Overview of the Development of Fibre Metal Laminates, Appl. Compos. Mater., 10(4-5), pp. 189-205, DOI: 10.1023/A:1025533701806.

[2] Xu, R., Huang, Y., Lin, Y., Bai, B., Huang, T. (2017). In-plane flexural behaviour and failure prediction of carbon fibrereinforced aluminium laminates, J. Reinf. Plast. Compos., 36(18), pp. 1384-1399, DOI: 10.1177/0731684417708871.

[3] Botelho, E.C., Silva, R.A., Pardini, L.C., Rezende, M.C. (2006). A Review on the Development and Properties of Continuous Fiber/epoxy/aluminum Hybrid Composites for Aircraft Structures, Mater. Res., 9(3), pp. 247-256, DOI: $10.1002 /$ ar.1092200206.

[4] Kim, J.G., Kim, H.C., Kwon, J.B., Shin, D.K., Lee, J.J., Huh, H. (2015). Tensile behavior of aluminum/carbon fiber reinforced polymer hybrid composites at intermediate strain rates, J. Compos. Mater., 49(10), pp. 1179-1193, DOI: $10.1177 / 0021998314531310$.

[5] Sorrentino, L., Bellini, C., Corrado, A., Polini, W., Aricò, R. (2015).Ballistic performance evaluation of composite laminates in kevlar 29. Procedia Engineering, vol. 88, Elsevier B.V., pp. 255-262.

[6] Frizzell, R.M., McCarthy, C.T., McCarthy, M.A. (2008). An experimental investigation into the progression of damage in pin-loaded fibre metal laminates, Compos. Part B Eng., 39(6), pp. 907-925, DOI: 10.1016/j.compositesb.2008.01.007.

[7] Hu, Y.B., Li, H.G., Cai, L., Zhu, J.P., Pan, L., Xu, J., Tao, J. (2015). Preparation and properties of Fibre-Metal Laminates based on carbon fibre reinforced PMR polyimide, Compos. Part B Eng., 69, pp. 587-591, DOI: 10.1016/j.compositesb.2014.11.011.

[8] Lawcock, G., Ye, L., Mai, Y.W., Sun, C.T. (1997). The effect of adhesive bonding between aluminum and composite prepreg on the mechanical properties of carbon-fiber-reinforced metal laminates, Compos. Sci. Technol., 57(1), pp. 3545, DOI: 10.1016/S0266-3538(96)00107-8.

[9] Botelho, E.C., Silva, R.A., Pardini, L.C., Rezende, M.C. (2004). Evaluation of adhesion of continuous fiber-epoxy composite/aluminum laminates, J. Adhes. Sci. Technol., 18(15-16), pp. 1799-1813, DOI: 10.1163/1568561042708377.

[10] Dhaliwal, G.S., Newaz, G.M. (2016). Experimental and numerical investigation of flexural behavior of carbon fiber reinforced aluminum laminates, J. Reinf. Plast. Compos., 35(12), pp. 945-956, DOI: 10.1177/0731684416632606.

[11] Wu, X., Pan, Y., Wu, G., Huang, Z., Tian, R., Sun, S. (2017). Flexural behaviour of CFRP/Mg hybrid laminates with different layers thickness, Adv. Compos. Lett., 26(5), pp. 168-172.

[12] Sorrentino, L., Polini, W., Bellini, C., Parodo, G. (2018). Surface treatment of CFRP: influence on single lap joint 
performances, Int. J. Adhes. Adhes., 85, pp. 225-233, DOI: 10.1016/j.ijadhadh.2018.06.008.

[13] Bellini, C., Parodo, G., Polini, W., Sorrentino, L. (2018). Influence of hydrothermal ageing on single lap bonded CFRP joints, Frat. Ed Integrità Strutt., 45, pp. 173-182, DOI: 10.3221/IGF-ESIS.45.15.

[14] Pärnänen, T., Alderliesten, R., Rans, C., Brander, T., Saarela, O. (2012). Applicability of AZ31B-H24 magnesium in Fibre Metal Laminates - An experimental impact research, Compos. Part A Appl. Sci. Manuf., 43(9), pp. 1578-1586, DOI: 10.1016/j.compositesa.2012.04.008.

[15] Sadighi, M., Pärnänen, T., Alderliesten, R.C., Sayeaftabi, M., Benedictus, R. (2012). Experimental and numerical investigation of metal type and thickness effects on the impact resistance of fiber metal laminates, Appl. Compos. Mater., 19(3-4), pp. 545-559, DOI: 10.1007/s10443-011-9235-6.

[16] Cortés, P., Cantwell, W.J. (2005). The fracture properties of a fibre-metal laminate based on magnesium alloy, Compos. Part B Eng., 37(2-3), pp. 163-170, DOI: 10.1016/j.compositesb.2005.06.002.

[17] Ahmadi, H., Sabouri, H., Liaghat, G., Bidkhori, E. (2011). Experimental and numerical investigation on the high velocity impact response of GLARE with different thickness ratio, Procedia Eng., 10, pp. 869-784, DOI: $10.1016 / j \cdot$ proeng.2011.04.143.

[18] Sorrentino, L., Bellini, C., Carrino, L., Leone, A., Mostarda, E., Tersigni, L. (2009).Cure Process Design to manufacture composite components with variable thickness by a closed die technology. 17th International Conference on Composite Materials, Edinburgh.

[19] Sorrentino, L., Bellini, C. (2016). In-process monitoring of cure degree by coplanar plate sensors, Int. J. Adv. Manuf. Technol., 86(9-12), pp. 2851-2859, DOI: 10.1007/s00170-016-8338-5.

[20] Sathyaseelan, P., Logesh, K., Venketasudhahar, M., Dilip Raja, N.. (2015). Experimental and Finite Element Analysis of Fibre Metal Laminates (FML'S) Subjected to Tensile, Flexural and Impact Loadings with Different Stacking Sequence, Int. J. Mech. Mechatronics Eng., 15(03), pp. 23-27.

[21] Hamill, L., Hofmann, D.C., Nutt, S. (2018). Galvanic Corrosion and Mechanical Behavior of Fiber Metal Laminates of Metallic Glass and Carbon Fiber Composites, Adv. Eng. Mater., 20(2), pp. 1-8, DOI: 10.1002/adem.201700711.

[22] Pan, L., Ali, A., Wang, Y., Zheng, Z., Lv, Y. (2017). Characterization of effects of heat treated anodized film on the properties of hygrothermally aged AA5083-based fiber-metal laminates, Compos. Struct., 167, pp. 112-122, DOI: 10.1016/j.compstruct.2017.01.066.

[23] Rajan, B.M.C., Kumar, A.S. (2018). The Influence of the Thickness and Areal Density on the Mechanical Properties of Carbon Fibre Reinforced Aluminium Laminates (CARAL), Trans. Indian Inst. Met., 71(9), pp. 2165-2171, DOI: $10.1007 /$ s12666-018-1348-2.

[24] Hamill, L., Nutt, S. (2018). Adhesion of metallic glass and epoxy in composite-metal bonding, Compos. Part B Eng., 134, pp. 186-192, DOI: 10.1016/j.compositesb.2017.09.044.

[25] Li, H., Hu, Y., Fu, X., Zheng, X., Liu, H., Tao, J. (2016). Effect of adhesive quantity on failure behavior and mechanical properties of fiber metal laminates based on the aluminum-lithium alloy, Compos. Struct., 152, pp. 687-692, DOI: $10.1016 /$ j.compstruct.2016.05.098. 